\section{Covid-19: I'habitatge protegeix la gent gran a Amèrica Llatina? Argentina i Colòmbia comparades amb Espanya}

Juan A. Módenes, Centre d'Estudis Demogràfics i Dept. de Geografia, Universitat Autònoma de Barcelona (ESP), Mariana Marcos, Universidad de Buenos Aires, Consejo de Investigaciones Científicas y Técnicas i Universidad Nacional de Tres de Febrero (ARG) $i$ Diva Marcela García, Pontificia Universidad Javeriana i Universidad Externado de Colombia (COL)

En aquest nou paradigma de la covid-19, protegir la població més gran no pot confiar-se només al seu confinament a l'habitatge, i menys encara a Amèrica Llatina. L'estructura de les llars, les característiques de l'habitatge i l'activitat laboral dels coresidents condicionen l'exposició de les persones grans als contagis dins de l'habitatge. Per mesurar aquesta exposició, aquest Perspectives Demogràfiques proposa el càlcul d'un indicador que estima el risc residencial multidimensional, que permet la comparació entre poblacions. Més de la meitat de la gent gran de Colòmbia i un $35 \%$ de la d’Argentina es troba sobreexposada a la covid-19 a casa. El nostre estudi demostra que el risc residencial és molt important a Amèrica Llatina, però també significatiu a Espanya pel que, un dels objectius prioritaris en la protecció de les persones grans ha de ser el de minimitzar aquest risc residencial. L’indicador de risc residencial davant la covid-19 pot utilitzar-se per identificar àrees o subpoblacions més exposades dins dels països i guiar la futura acció política davant la pandèmia.

\section{LES PERSONES GRANS DAVANT LA COVID-19 AAMĖRICA LLATINA}

La covid-19 ha impactat de ple en la població més gran. Constitueix el principal grup de risc perquè tenen una simptomatologia més greu i una letalitat molt més alta. Pel que fa a Amèrica Llatina, l'avantatge del moderat envelliment de la població es veurà negativament compensat per la major prevalença de malalties cròniques i a edats més joves, la desigualtat, les menors possibilitats de distanciament social (Acosta, 2020) i a la concentració espacial de la població en grans ciutats i amb alts nivells de segregació.

Mentre no s'obtingui una curació efectiva, és fonamental protegir a la gent gran, tant en l'actual com en futures onades (Huenchuan, 2020). Aquesta protecció ha de consistir en contenir el contagi primari però, sobretot, en disminuir els contagis secundaris per transmissió intrafamiliar dins les llars (Esteve et al, 2020; Mogi, Spijker 2020). A Amèrica Llatina les morts per contagi secundari podrien duplicar les produïdes per contacte primari (Esteve et al, 2020). Mentre que a Europa la malaltia ha afectat amb més intensitat a les persones grans institucionalitzades, tot manifestant els problemes d'aquest model de cura (Comas-Herrera, Zalakain, 2020), a Amèrica Llatina els grans viuen menys en institucions però solen coresidir en estructures familiars complexes, de caràcter intergeneracional (Saad, 2005). En elles, les persones difícilment poden aillar-se per complet. A més, cal afegir-hi els riscos que aporten els coresidents que han de sortir a treballar, sovint en condicions d'informalitat, precarietat i amb escasses possibilitats de teletreball.

La forta desigualtat social a Amèrica Llatina agreuja, per a

FIGURA 1. Persones de 65 anys i més segons risc residencial davant la covid-19. Colòmbia, Argentina i Espanya

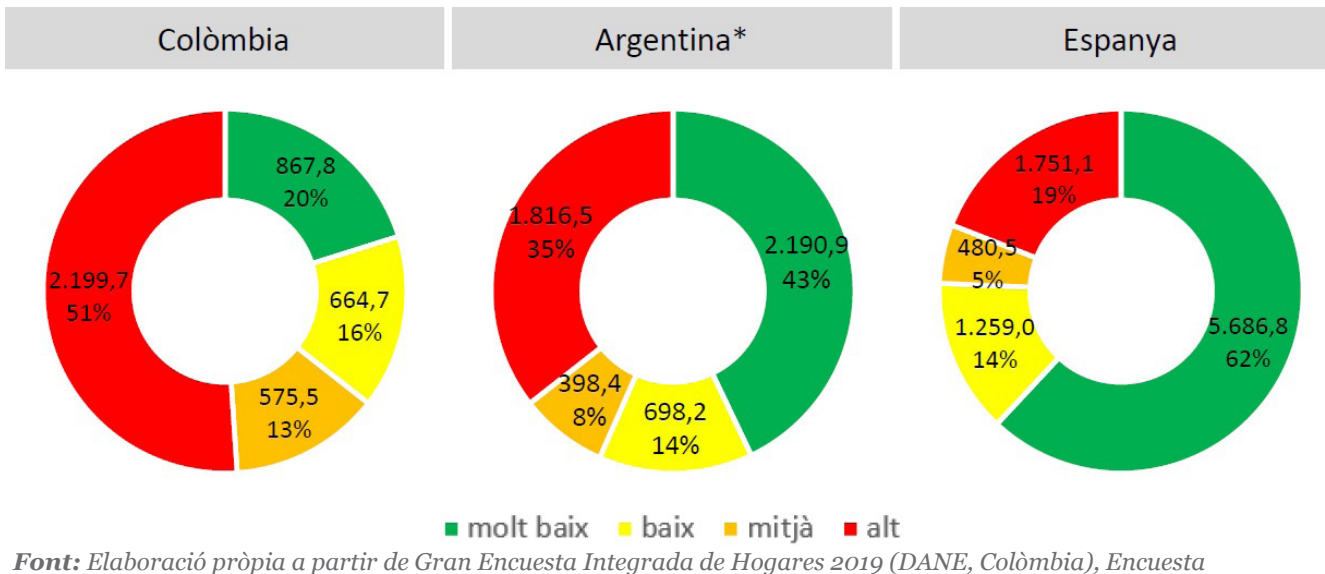

Font: Elaboració pròpia a partir de Gran Encuesta Integrada de Hogares 2019 (DANE, Colòmbia), Encuesta

Permanente de Hogares $1^{\circ}$ semestre 2019 i Proyecciones 2010 (INDEC, Argentina) i Encuesta de Condiciones de Vida 2018 (INE, Espanya).

*Enquesta representativa del $73 \%$ de les persones grans. Absoluts estimats en base a projeccions. 
molts, els riscos de contraure la covid-19 (CEPAL, 2020). En els grups socioeconòmics més baixos, s’intensifiquen els riscos residencials que comporten les llars de grans dimensions, la convivència intergeneracional, la mala qualitat de l'habitatge, la necessitat de treballar de la gent gran i l'ocupació informal, precària i de baixa qualificació dels coresidents. Avançar en la lluita contra la malaltia implicarà prioritzar la protecció de les persones grans en entorns de vulnerabilitat social. I això obliga a avaluar la situació de partida d'aquesta població a Amèrica Llatina i les desigualtats a diferents escales. D'aquí el nostre interès en contrastar dos casos representatius i diferents, Colòmbia i Argentina. Per acabar de comprendre i contextualitzar els resultats, els compararem amb els d'Espanya.

En aquest treball inicial, aportem un mètode que permet sintetitzar els riscos de contagi a l'habitatge. Els resultats més generals (figura 1) són molt reveladors. Mentre a Colòmbia el $51 \%$ dels majors estan sotmesos a un risc residencial alt davant la covid-19, aquest percentatge baixa a un $35 \%$ a l'Argentina i fins a un $19 \%$ a Espanya. D'altra banda, només un $21 \%$ dels majors colombians tindrien un risc molt baix, sent del $42 \%$ a l'Argentina i del 62\% a Espanya.

\section{MESURAR EL RISC RESIDENCIAL}

El nostre indicador permet quantificar el risc de tenir contacte domèstic amb la malaltia covid-19. S'ha calculat a partir d'una sèrie de dimensions familiars, residencials i laborals relacionades

FIGURA 2. Definició dels nivells de risc residencial davant la covid-19 en funció de les condicions de coresidència, habitatge i laborals

\begin{tabular}{|c|c|c|c|}
\hline $\begin{array}{l}\text { Tipus de } \\
\text { coresidència a } \\
\text { I'habitatge }\end{array}$ & $\begin{array}{l}\text { Condiciones de risc } \\
\text { a l'habitatge }\end{array}$ & $\begin{array}{l}\text { Probabilitat de que } \\
\text { algun resident no } \\
\text { pugui teletreballar }\end{array}$ & $\begin{array}{l}\text { Condicions de } \\
\text { risc residencial }\end{array}$ \\
\hline unipersonal o parella & sense sobreocupació & ningú treballa & davant la c \\
\hline sola, única llar a & per habitació i amb & baixa & \\
\hline I'habitatge & aigua corrent a & mitjana & \\
\hline & I'habitatge & alta & \\
\hline & amb sobreocupació & ningú treballa & mínimes \\
\hline & per habitació i sense & baixa & baixes \\
\hline & aigua corrent a & mitjana & \\
\hline & l'habitatge & alta & tjanes \\
\hline altre tipus de & sense sobreocupació & ningú treballa & altes \\
\hline coresidència & per habitació i amb & baixa & \\
\hline & aigua corrent a & mitjana & \\
\hline & I'habitatge & alta & \\
\hline & amb sobreocupació & ningú treballa & \\
\hline & per habitació i sense & baixa & \\
\hline & aigua corrent a & mitjana & \\
\hline & I'habitatge & alta & \\
\hline
\end{tabular}

amb la protecció que ofereix l'habitatge a la gent gran (figura 2). És el que anomenem risc residencial. En primer lloc es mesura la distribució de persones grans segons convisquin en llars unipersonals, soles amb la parella (menys risc) o amb la parella i altres persones (més risc). En segon lloc, s'estima si es resideix en un habitatge en condicions d'amuntegament (més de 2 persones de mitjana per dormitori, més risc) $i$ amb dèficit de subministraments essencials (sense aigua corrent, més risc) o no -dimensió especialment rellevant a Amèrica Llatina-. En tercer lloc, s'identifica si, dins de l'habitatge, hi ha persones que treballen, incloent-hi les de més edat (més risc) o no. I, per completar aquesta tercera dimensió, considerem fins a quin punt les feines dels membres de la llar els obliguen a sortir de l'habitatge (més risc) o si es poden teletreballar (posicions socials més altes i de menor risc). El risc residencial total serà més elevat com més dimensions individuals de risc es combinin.

Com a fonts, s'han emprat enquestes sociodemogràfiques dels tres països que compleixen els requisits de ser actuals, comparables i integrar les dimensions comentades. En el cas de Colòmbia s'ha utilitzat la Gran Encuesta Integrada de Hogares de 2019; per Argentina, l'Encuesta Permanente de Hogares del 1r semestre 2019 i les Proyecciones de Población 2010; i per Espanya, s'ha explotat l'Encuesta de Condiciones de Vida de 2018. L'univers d'estudi engloba a les persones que en el moment de l'enquesta tenien 65 anys i més, i vivien en llars particulars.

Una tasca important ha estat estimar la probabilitat de que, una persona ocupada, pugui teletreballar o, al contrari, estigui obligada a sortir de l'habitatge. Ens hem basat en Bonavida i Gasparini (2020) que han estudiat la probabilitat que cada ocupació (2 dígits, codi internacional CIUO) pogués efectuar-se amb la modalitat de teletreball. Hem aplicat els seus resultats als tres països per calcular la probabilitat composta que en una unitat de coresidència, alguna persona hagués de treballar fora de casa. Aquesta probabilitat tendeix a ser major com més treballadors conviuen en l'habitatge, pel que també està associada positivament a la mida del grup domèstic.

Un cop combinades totes les dimensions s'ha obtingut una parametrització jeràrquica, del risc residencial de les persones grans en el 
seu habitatge. La figura 2 presenta aquesta "semaforització" del risc. Si la persona gran viu sola o amb la seva parella sense ningú més i sense cap més llar a l'habitatge, amb unes condicions d'habitabilitat adequades i on cap dels seus membres treballa, el risc és molt baix. Òbviament sempre hi haurà un risc de contagi, sigui per infecció primària al principi d'un brot, o sigui perquè en confinament o en altres etapes de control, la reclusió no sol ser absoluta. Activitats puntuals al carrer, com ara comprar queviures, poden significar un cert risc. A l'altre extrem, el risc és alt quan la persona gran viu amb altres membres, en particular amb algú que hagi de treballar fora del domicili, o si ella mateixa ho ha de fer, i l'habitatge està sobreocupat o no disposa d'aigua corrent.

Segons les dades de cadascuna de les dimensions de risc residencial (figura 3), a Colòmbia el 67\% de les persones grans comparteixen el seu habitatge amb algú diferent a la seva parella. Només el $38 \%$ resideix en llars on ningú treballa i un $52 \%$ comparteix el seu habitatge amb algú que, molt probablement, ha de sortir a treballar. A més, un 14,6\% dels majors colombians es troben en habitatges sobreocupats o sense servei d'aigua. A l’Argentina, en canvi, els riscos residencials són menors, però

FIGURA 3. Persones de 65 anys i més segons condicions de coresidència, habitatge i laborals. Colòmbia, Argentina i Espanya

Dimensió de risc
Risc de la llar
no és unipersonal/parella sola
o hi ha més d'una llar
- unipersonal o parella sola,
Ilar única a l'habitatage
- altre tipus de coresidència

- altre tipus de coresidència

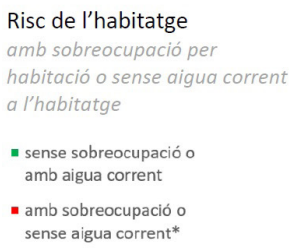

Risc per activitat laboral hi ha ocupats a l'habitatge amb baixes probabilitats de poder teletreballar

- ningú treballa = risc mitjà "risc baix - risc alt

- hi ha ocupat(de)s sense dades**
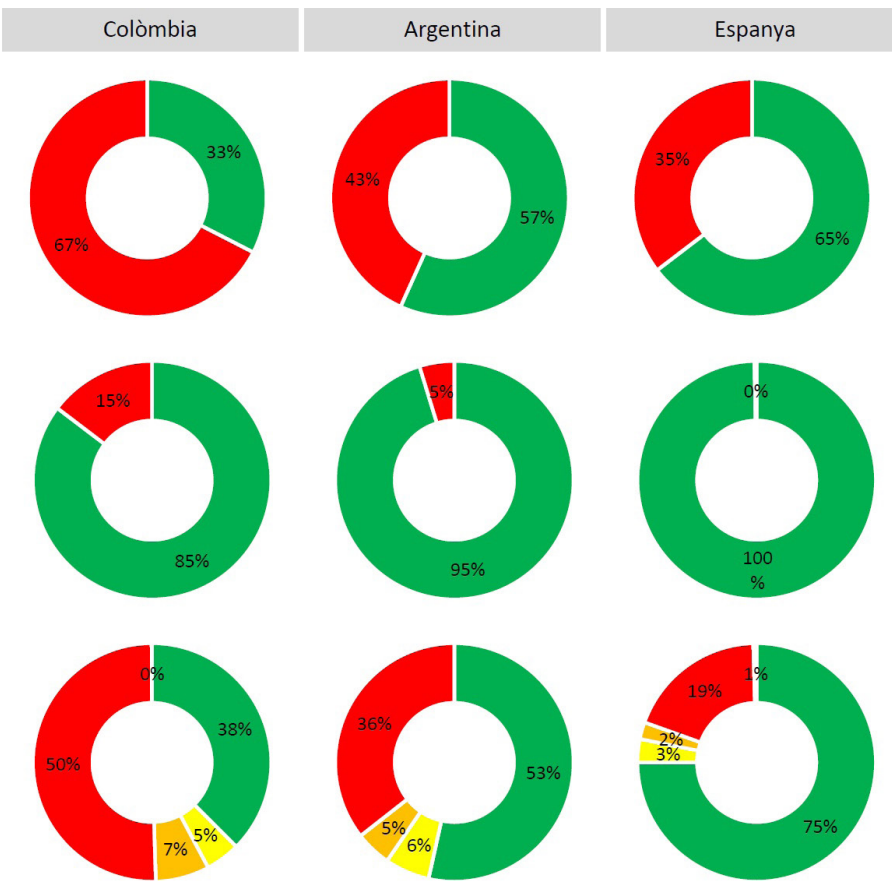

Font: Elaboració pròpia a partir de Gran Encuesta Integrada de Hogares 2019 (DANE, Colòmbia), Encuesta Permanente de Hogares $1 r$ semestre 2019 (INDEC, Argentina) i Encuesta de Condiciones de Vida 2018 (INE, Espanya)

* Argentina: inclou persones en una "villa"

** Argentina: en absència de dades d'ocupació, risc per a no poder teletreballar imputat a partir de la branca d'activitat també importants: un $43 \%$ de les persones grans comparteix el seu habitatge amb persones diferents a la seva parella i només un $54 \%$ dels grans viuen en un habitatge on ningú treballa. Un 35\% conviu amb algú que és molt probable que es vegi obligat a sortir de casa per treballar. I, en un $5 \%$ de casos, l'habitatge es troba sobreocupat o sense aigua corrent.

A Espanya, en termes relatius, tots els paràmetres són més favorables. Gairebé dos terços de les persones grans habiten en llars unipersonals o amb parella i, en gairebé el cent per cent dels casos, sense sobreocupació. D’altra banda, un $75 \%$ resideixen en llars on ningú treballa i en un $80 \%$, en llars on és poc probable que algú hagi d'anar a treballar fora de l'habitatge.

Els resultats apunten diverses línies. En primer lloc, a Amèrica Llatina la freqüent coresidència intergeneracional és decisiva per calcular el risc. A Espanya l'autonomia residencial generalitzada de les persones grans, pot actuar com un factor protector del contagi dins de l'habitatge. A Amèrica Llatina, en canvi, el grau d'autonomia residencial es relaciona amb l'estructura social. En segon lloc, quan els grans conviuen amb persones més joves, el risc relacionat amb l'activitat laboral s'incrementa. I això s'agreuja quan és la pròpia persona gran la que ha de treballar (en absència de protecció d'ocupació formal o prestacions adequades per jubilació).

Tot i que a Espanya, les condicions són millors i la seva població total similar a la d'Argentina i Colòmbia, el seu major envelliment eleva considerablement les xifres absolutes de gent gran en risc residencial. Així, a Colòmbia viuen en risc alt 2 milions de persones de 65 anys i més, a l'Argentina s'estima que són 1,8 milions i a Espanya 1,7 milions. Així, el risc que la gent gran estigui en contacte, dins de l'habitatge, amb la malaltia és elevat en els tres països considerats. No és una cosa puntual sinó estructural.

\section{PROTEGIR LA GENT GRAN}

Hem mostrat que no és bona estratègia confiar només en l'eficàcia del confinament per protegir els grups de la població amb un risc superior. Els riscos residencials de la gent gran no són menyspreables en cap context, però són molt més elevats 
a Amèrica Llatina. Els contactes quotidians entre les persones, properes o no, són multidimensionals i difícils d'evitar-los del tot, quan els grans no viuen sols o en parella. En aquest estudi hem abordat algunes dimensions crítiques d'aquest contacte social: la convivència a l'habitatge, la seva qualitat i la necessitat de realitzar l'activitat laboral fora de la llar. I, concretament, hem proposat un indicador de risc residencial a partir de variables que mesuren les dimensions anteriors, i expressa la vulnerabilitat de la gent gran en el seu context domèstic. Ho hem aplicat a Colòmbia i a Argentina, que mostren l'especificitat d'Amèrica Llatina en comparació amb Espanya, un país europeu, i, alhora, l'heterogeneïtat interna de la regió.

Tot i que la població anciana no sol viure amuntegada, la incidència d'aquest problema (tot i que sigui baixa) és suficient per dificultar els confinaments generals obligatoris o l'eventual necessitat d'aillament individual. A Amèrica Llatina la feble protecció social també obliga a moltes persones grans a continuar treballant, sovint en ocupacions de baixa qualificació i en condicions d'informalitat. Si no és el cas, la coresidència amb persones més joves i amb altres llars dins l'habitatge, les posa freqüentment en contacte amb les que han i necessiten sortir a treballar. Pautes complexes de coresidència estan associades a situacions laborals de la llar més precàries i amb més dificultats per minimitzar el contacte social. En definitiva, qualsevol mesura de protecció de la gent gran ha d'anticipar que aillar-la completament de persones de menys risc però major exposició, és poc realista i, no poques vegades, contraproduent. A més, els resultats mostren que les situacions intermèdies de risc són minoritàries, de manera que hi ha una certa polarització del risc residencial que caldrà considerar.

El nostre mètode aconsegueix detallar els riscos residencials per altres variables rellevants, com l'edat, el sexe, els grups socials i els àmbits geogràfics. Replicat en base a dades censals, també afegeix el potencial d'identificar les àrees on es concentren més aquests riscos, en relació amb la gran heterogeneïtat de les estructures sociodemogràfiques i residencials d'Amèrica Llatina. Al mateix temps, resulta fonamental, a més llarg termini, per planificar futurs escenaris de protecció d'aquest o altres grups de risc en l'eventualitat de nous episodis de transmissió de malalties infeccioses. I finalment, permet l'avaluació comparativa d'aquests nous reptes als quals ens enfrontem.

\section{Referències bibliogràfiques}

Acosta, E. (2020) Seminario Virtual "Epidemias en América Latina: historia y presente". Programa de Población, Facultad de Ciencias Sociales, Udelar, 12-5-2020.

Bonavida, C.; Gasparini, L. (2020) "E Impacto Asimétrico de la Cuarentena". Documentos de Trabajo del CEDLAS, 261, CEDLAS-FCE-UNLP (http://www. cedlas.econo.unlp.edu.ar/wp/no-261/).

CEPAL (2020) El desafío social en tiempos del covid-19. Informe especial (https://repositorio.cepal.org/handle/11362/45527)

Comas-Herrera A.; Zalakain J. (2020) Mortality associated with COVID-19 outbreaks in care homes: early international evidence. LTCcovid.org, International Long-Term Care Policy Network, CPEC-LSE, April (https://ltccovid.org/ wp-content/uploads/2020/o4/Mortality-associated-with-COVID-12-April-2. pdf).

Esteve, A.; Permanyer, I.; Boertien, D Vaupel, J. (2020) "National age and coresidence patterns shape covid-19 vulnerability". medRxiv (https://doi.org/ 0.1101/2020.05.13.20100289).
Huenchuan S. (2020) Covid 19: recomendaciones generales para la atención a personas mayores desde una perspectiva de derechos humanos. México: CEPAL (https://repositorio.cepal. org/bitstream/handle/11362/45316/4/ S2000271_es.pdf).

Mogi, R.; Spijker, J. (2020) "The influence of social and economic ties to the spread of COVID-19 in Europe". SocArXiv (https://doi.org/10.31235/ osf.io/sb8xn)

Cito

Juan A. Módenes, Mariana Marcos, Diva Marcela García (2020) "Covid-19: l'habitatge protegeix la gent gran a Amèrica Llatina? Argentina i Colòmbia comparades amb Espanya". Perspectives Demogràfiques, 20 : 1-4 (ISSN: 2696-4228) (https://doi. org/10.46710/ced.pd.cat.20)

ISSN

ISSN 2696-4228

Editors

Andreu Domingo i Albert Esteve (Centre d'Estudis Demogràfics)
Correspondència dirigida a

\section{Juan A. Módenes}

jamodenes@ced.uab.es

Mariana Marcos

mmarcos@conicet.gov.ar

Diva Marcela García

diva.garcia@javeriana.edu.co

\section{Agraïments}

Aquest informe s'inscriu en els projectes $\mathrm{R}+\mathrm{D}+\mathrm{I}$ "Comportamientos demográficos y estrategias residenciales: apuntes para el desarrollo de nuevas políticas sociales" (CSO2016-79142-R, Espanya) i "Desigualdades microespaciales urbanas" (32/375 A, UNTREF, Argentina). S'agraeix al Centre d'Estudis Demogràfics (CERCA Programme ( Generalitat de Catalunya) pel seu suport, especialment de la responsable del banc de dades Tere Menacho. L'autoria també agraeix l'ajuda de Maru Fernández, Jimena Johan, Florència Ansaloni i Alejandra Hernández.

Crèdits

Gràfics: Mariana Marcos

Maquetació: Xavier Ruiz Vilchez
Enllaç url

http://ced.uab.es/difusion/butlletiperspectives-demografiques

\section{Contacte}

Centre d'Estudis Demogràfics. Carrer de Ca n'Altayó, Edifici E2 Universitat Autònoma de Barcelona o8193 Bellaterra / Barcelona Espanya

Telèfon: +34 935813060 Correu:demog@ced.uab.es Web: http://ced.uab.es/ 